\title{
A Review of the Dermatological Manifestations of Coronavirus Disease 2019 (COVID-19)
}

\author{
Farah Marraha $\mathbb{D D}^{1,2}$ Ibtissam Al Faker, ${ }^{1,2}$ and Salim Gallouj ${ }^{1,2}$ \\ ${ }^{1}$ Department of Dermatology, University Hospital Center of Tangier, Tetouan, Al Hoceima, Morocco \\ ${ }^{2}$ Faculty of Medicine and Pharmacy Tangier, Abdelmalek Essaadi University, Tangier, Morocco \\ Correspondence should be addressed to Farah Marraha; farahmarraha90@gmail.com
}

Received 13 May 2020; Revised 11 July 2020; Accepted 21 July 2020; Published 11 August 2020

Academic Editor: E. Helen Kemp

Copyright ( 92020 Farah Marraha et al. This is an open access article distributed under the Creative Commons Attribution License, which permits unrestricted use, distribution, and reproduction in any medium, provided the original work is properly cited.

Coronavirus disease 2019 (COVID-19) caused by severe acute respiratory syndrome coronavirus-2 (SARS-CoV-2) has affected 210 countries and territories around the world. The virus has spread rapidly, and the disease is still extending up to now. The pathophysiology for SARS-CoV-2 has not been well elucidated, and diverse hypotheses to date have been proposed. Initially, no skin manifestations were observed among patients with COVID-19, but recently a few cases have been described. In this review, we discuss these various cutaneous manifestations and skin problems related to personal protective equipment, as well as different cutaneous anti-COVID-19 drug-associated reactions. We also focus on the currently proposed managements of these rare manifestations.

\section{Introduction}

The first case infected by severe acute respiratory syndrome coronavirus-2 (SARS-CoV-2) was reported in Wuhan, China, in late November 2019. In December 2019, several patients have been presented to the hospital for acute pneumonia of unknown origin [1]. Later, SARS-CoV-2 has been found in the lower respiratory tract of hospitalized patients, and the World Health Organization (WHO) recognized the disease as COVID-19 (Coronavirus Disease 2019) on January 12,2020 . The virus has spread rapidly, and the condition is still extending up to now. On March 11, the WHO declares the COVID-19 outbreak as pandemic [2]. We are still counting to this day 11,577,979 confirmed cases with 537,103 deaths worldwide. Initially, no skin manifestations were observed among patients with COVID-19 [2,3]. The first case was described in Thailand with petechiae rash mimicking a dengue fever [4], and then a few other cases followed [2-5]. These skin lesions can guide clinicians for diagnosis if the patients present other COVID-19 symptoms; however, viral infection cannot be the only cause; mediated inflammatory responses and drug reactions can also be suspected. The aim of our literature review is to report the various cutaneous manifestations described to date associated with COVID-19, the skin problems related to personal protective equipment, and the different cutaneous antiCOVID-19 drug reactions [6, 7]. We also discuss the different interventions proposed to manage these patients $[8,9]$ and solutions to protect skin and mucous membrane barriers for healthcare workers [10-12].

\section{Epidemiology, Pathogenesis, and Diagnosis of COVID-19: An Overview}

Since the epidemic began in Europe, some countries have presented virus-spreading indicators higher than others. In Italy, the first cases were detected in the last ten days of February. Its case fatality rate at present is $14.4 \%$. In France, the mortality rate has continued to increase, reaching $17.9 \%$ (July 6, 2020). In the United States, the first cases appeared around March 10. The country represents more than $25 \%$ of the cumulative cases worldwide. As for Morocco, the first case emerged on March 2; official indicators seem to display volatile trends. It is tough to demonstrate a correlation between them. The growth factor can vary from a value of 2 to a value of 0.5 within 24 hours. The contamination rate 
displayed every day (new cases in 24 hours compared to the number of tests carried out in 24 hours) is also very volatile ranging from $9 \%$ on March 28 to $30 \%$ on April 8 and $2.2 \%$ on July 5 . As for the mortality rate, it decreased from $6.2 \%$ to 1.6\% lately (July 6, 2020) [13].

The pathophysiology of COVID-19 has not been well elucidated, but it seems similar to that of SARS-CoV [14]. SARS-CoV has the appearance of a crown under electron microscope. It is composed of genomic RNA and four structural proteins: spike (S), envelope (E), membrane (M), and nucleocapsid $(\mathrm{N})$. It can attach to the host cell by binding its $\mathrm{S}$ protein to the receptor protein membrane [15-18]. A number of studies showed that angiotensinconverting enzyme 2 (ACE2) is a receptor on the host cell membrane, with a high affinity to SARS-CoV-2 protein (S) $[19,20]$. Yet, the significance of this binding affinity is still under intensive research study [17]. ACE2 is shown to be expressed by epithelial cells of the intestine, kidney, blood vessels, and most abundantly in type II alveolar cells of the lungs [19, 20]. Importantly, Hamming et al. [20] demonstrated that ACE2 is also present in the basal cell layer of the epidermis extending to the basal cell layer of hair follicles, which might explain the cutaneous manifestation of COVID-19. Decreased ACE2 function can cause dysfunction of the renin-angiotensin system (RAS) and intensify inflammation, vascular permeability, and neutrophil accumulation [14, 21]. Rapid viral replication can also cause cellular apoptosis and triggers a cascade of inflammatory reaction, as well as an increase in cytokine and chemokine blood levels [21]. Therefore, the inflammatory response of the body also plays a crucial role in SARS-CoV-2-induced lung injury cases, since the high production of these cytokines is responsible for the accumulation of cells and fluids (cytokine storm) [18]. These cytokines arriving at the skin and reaching the various cells of the cutaneous immune system can cause the dermatological lesions described during COVID-19 infection (urticarial lesion, erythema, and vesicles) [22].

Wenzhong et al.'s latest hypothesis suggests that lung damage and inflammation are secondary to extreme lung cell poisoning [23]. In fact, ORF8, a SARS-CoV-transcribed nonstructural protein, could bind to porphyrin as well as other proteins and can attack the heme on the 1-beta chain of hemoglobin. Consequently, this will decrease hemoglobin and gas exchanges, which eventually results in ground-glasslike lung images.

Several cases of patients with COVID-19 showed leucopenia, lymphocytopenia, increased D-dimer level, and prolonged prothrombin $[1,17]$. Besides, abnormal findings of different organs function assessment may indicate multiorgan failure [17]. It has been suggested that COVID-19 is a zoonotic infection as the first infected people were exposed to the wet animal market in Wuhan city $[1,17]$. However, the intermediate host is still unknown. The virus is transmitted by inhalation of aerosol droplets from the infected patients $[1,17]$. The fecal-oral transmission was also hypothesized [21]. Therefore, it is essential to strictly adhere to environmental and hand hygiene to control the infection [24]. So far, the golden clinical diagnosis methods to confirm cases of
COVID-19 include the detection of nucleic acids in the nasal and throat swab sampling by real-time polymerase chain reaction (PCR) [25]. The identification of SARS-CoV-2specific IgM and IgG antibodies can also be useful for diagnosis [17].

\section{Cutaneous Manifestations in COVID- 19 Patients}

The most common symptoms in COVID-19 are fever, fatigue, and dry cough, succeeded by other symptoms, such as headache, nasal congestion, sore throat, myalgia, and arthralgia [1, 26]. Initially, no skin involvement during COVID infection was observed, but more recently, some cases (Table 1) have been reported $[2,4,5,11]$, as well as the skin problems related to personal protective equipment. Secondary skin reactions to the different treatments suggested are also possible.

3.1. Skin Lesions and COVID-19. The frequency of the skin lesions associated with COVID-19 infection varies according to the series; in a Chinese study of 1099 positive cases, the incidence was only $0.2 \%$, while in an Italian series of 88 patients it was $20.4 \%$ [42].

Joob and Wiwanitkit described in Thailand, where the first case of COVID-19 outside of China was reported, a skin rash with petechiae in a case of COVID-19 [4]. Because of the frequent dengue cases in this country, it was the first diagnosis to be mentioned. After the appearance of other respiratory problems, COVID-19 has been diagnosed by RTPCR. In Italy, in a series of 148 cases, Recalcati reported, after the exclusion of 60 patients who have started new drugs in 15 previous days, that $20.5 \%$ of the 88 patients developed skin manifestations [2]. Eight of the 18 (44\%) had skin eruptions with symptoms in the beginning and the rest after hospitalization. Erythematous rashes were the most common sign (78\%) and then urticarial (3 cases) and chickenpox-like vesicles (1 case). However, no documentation has been assembled in these cases (photos or biopsy) to prevent the spread of infection. At the end of March, the French Society of Dermatology launched a call for a case, after discovering erythematous maculopapular lesions on the faces of three patients with a very probable or confirmed COVID-19 infection [5]. Finally, 113 cases have been reported, of which $74 \%$ of them had frostbite-like lesions.

An American team with a series of 505 patients with dermatological lesions tried to study the characteristics of pernio lesion or chilblain lesions in acral skin. Despite the absence of a confirmation test of COVID-19 infection in all these patients, the results showed that 318 of them had pernio-like lesions and most of them were young. The localization of these lesions was in the feet in $84 \%$ of the cases, in the hands in $5.1 \%$ of the cases, and in both in $10 \%$ of the cases [27].

In another Spanish study [30], including 20 children and adolescents with acral lesions, four clinical patterns were described: acral erythema (30\%) (Figure 1), dactylitis (20\%), purpuric maculopapules (35\%), and mixed pattern (15\%). 
TABLE 1: Summary of the published dermatological findings in COVID-19 patients.

\begin{tabular}{|c|c|c|c|c|}
\hline References & Journal & $\begin{array}{c}\text { Country of } \\
\text { origin }\end{array}$ & $\begin{array}{l}\text { Number of } \\
\text { cases }\end{array}$ & Dermatological findings \\
\hline Joob and Wiwanitkit, 2020 [4] & $\begin{array}{l}\text { Journal of the American } \\
\text { Academy of Dermatology }\end{array}$ & Thailand & 1 & Petechiae rash \\
\hline Recalcati et al., 2020 [2] & $\begin{array}{c}\text { Journal of the European } \\
\text { Academy of Dermatology and } \\
\text { Venereology }\end{array}$ & Italy & 18 & $\begin{array}{l}\text { Erythematous rash, widespread } \\
\text { urticaria, and chickenpox-like vesicles }\end{array}$ \\
\hline Zhang et al., 2020 [26] & $\begin{array}{c}\text { Zhonghua Xue Ye Xue Za Zhi (in } \\
\text { Chinese) }\end{array}$ & China & 7 & Acro-ischemia \\
\hline Beylot-Barry, 2020 [5] & $\begin{array}{c}\text { French Society of Dermatology } \\
\text { website }\end{array}$ & France & 113 & $\begin{array}{l}\text { Erythematous maculopapular lesions } \\
\text { on the face and pseudofrostbite }\end{array}$ \\
\hline Freeman et al., 2020 [27] & $\begin{array}{l}\text { Journal of the American } \\
\text { Academy of Dermatology }\end{array}$ & USA & 318 & Pernio-like lesions \\
\hline Piccolo et al., 2020 [28] & $\begin{array}{c}\text { Journal of the European } \\
\text { Academy of Dermatology and } \\
\text { Venereology }\end{array}$ & Italy & 54 & $\begin{array}{c}31 \text { of } 54 \text { had erythematous-edematous } \\
23 \text { of } 54 \text { had blistering lesions }\end{array}$ \\
\hline Roca-Ginés et al., 2020 [30] & British Journal of Dermatology & Spain & 375 & $\begin{array}{c}\text { Maculopapular eruptions } \\
\text { Urticarial lesions } \\
\text { Acral areas of erythema with vesicles } \\
\text { or pustules } \\
\text { Other vesicular eruptions } \\
\text { Livedo or necrosis } \\
\text { Acral erythema } \\
\text { Dactylitis } \\
\text { Purpuric maculopapules } \\
\text { Mixed pattern }\end{array}$ \\
\hline Fernandez-Nieto et al., 2020 [31] & $\begin{array}{c}\text { Journal of the European } \\
\text { Academy of Dermatology and } \\
\text { Venereology } \\
\text { Journal of the European }\end{array}$ & Spain & 1 & Urticarial rash \\
\hline Henry et al., 2020 [32] & $\begin{array}{c}\text { Academy of Dermatology and } \\
\text { Venereology } \\
\text { Journal of the European }\end{array}$ & France & 1 & Inaugural urticarial rash \\
\hline Estébanez et al., 2020 [33] & $\begin{array}{c}\text { Academy of Dermatology and } \\
\text { Venereology }\end{array}$ & Spain & 1 & Erythematous-yellowish papules \\
\hline Marzano et al., 2020 [34] & $\begin{array}{l}\text { Journal of the American } \\
\text { Academy of Dermatology }\end{array}$ & Italy & 22 & $\begin{array}{c}\text { Varicella-like papulovesicular } \\
\text { exanthem }\end{array}$ \\
\hline Genovese et al., 2020 [35] & Pediatric Dermatology & Italy & 8 & Papulovesicular skin eruption \\
\hline Fernandez-Nieto et al., 2020 [36] & $\begin{array}{l}\text { Journal of the American } \\
\text { Academy of Dermatology }\end{array}$ & Spain & $\begin{array}{l}95 \\
37\end{array}$ & $\begin{array}{c}\text { Chilblain-like lesions } \\
\text { Rounded erythematous macules and } \\
\text { vesicles }\end{array}$ \\
\hline Sanchez et al., 2020 [37] & JAMA Dermatology & France & 1 & Squamous and erythematous patch \\
\hline Pouletty et al., 2020 [38] & $\begin{array}{c}\text { Annals of the Rheumatic } \\
\text { Diseases }\end{array}$ & France & 16 & $\begin{array}{c}\text { Skin rash (Kawasaki-like syndrome), } \\
\text { edema with plantar and palmar } \\
\text { redness }\end{array}$ \\
\hline Bapst et al., 2020 [39] & BMJ Case Reports & Switzerland & 1 & Erythema multiforme \\
\hline Goren et al., 2020 [40] & Journal of Cosmetic Dermatology & USA & 41 & AGA \\
\hline Gaspari et al., 2020 [41] & $\begin{array}{c}\text { Journal of the European } \\
\text { Academy of Dermatology and } \\
\text { Venereology }\end{array}$ & Italy & 20 & $\begin{array}{c}\text { Sebopsoriasis } \\
\text { Facial herpes } \\
\text { Exanthem } \\
\text { Acral vasculitic eruption }\end{array}$ \\
\hline
\end{tabular}

RT-PCR could not confirm the presence of the virus. The authors believe that it is secondary to a realization of a diagnostic test at an early stage of the disease.

Coagulopathy and thrombocytopenia are also common complications for COVID-19 infection [17, 26, 43]. In Wuhan [26], patients with COVID-19 might present acroischemic lesions; there were 7 patients, in a critical situation, hospitalized in the intensive care unit with different clinical presentations, including finger/toe cyanosis, skin bulla, and dry gangrene. Four patients among them were diagnosed with definite disseminated intravascular coagulation (DIC). A team from Italy [28] tried to collect cases from a website, and 63 cases were collected, but only 54 pictures were analyzed: 31 of 54 patients had erythematous-edematous lesions and 23 of 54 had blistering lesions.

A report by Fernandez-Nieto et al. [36] describing the characterization of acute acro-ischemic lesions in 132 patients showed two different clinical presentations: chilblain- 


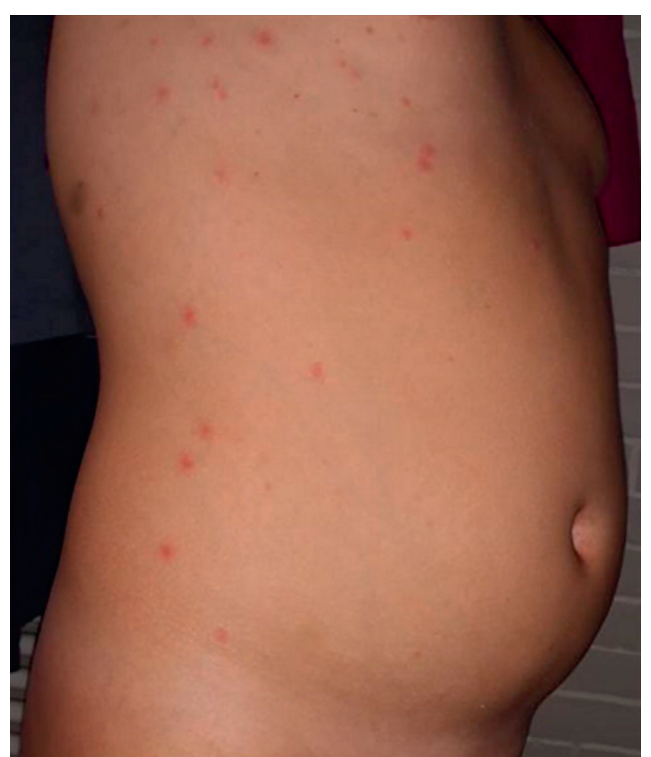

(a)

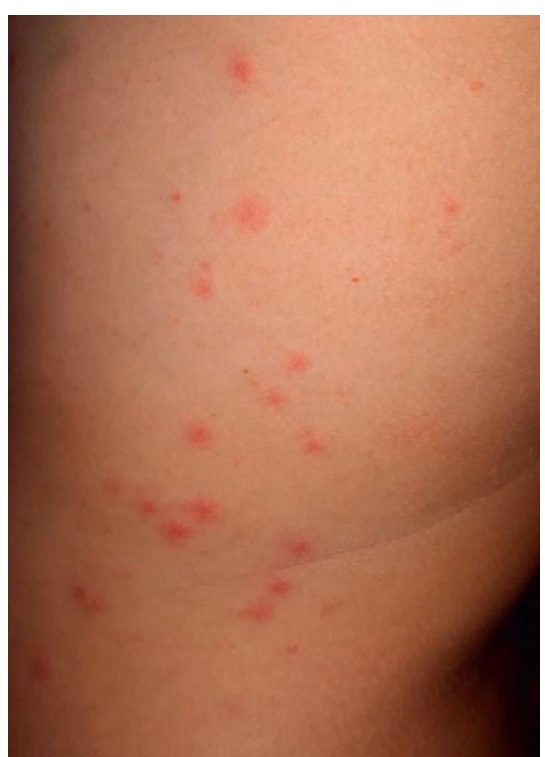

(b)

Figure 1: $(\mathrm{a}, \mathrm{b})$ Scattered erythematous papulovesicles on the trunk in a suspected COVID-19 patient (reprinted from Genovese et al. Varicella-like exanthem associated with COVID-19 in an 8-year-old girl: A diagnostic clue?, Pediatric Dermatology, 37(3), 435-436, Copyright (2020) [35], with permission from Wiley).

like in $72.0 \%$ of patients and the erythema multiforme-like in $28.0 \%$ of patients, all with distal localization.

Fernandez-Nieto et al. [31] described a patient in Madrid with an urticarial rash that appeared six days after the first symptoms. They also mentioned the presence of other cases with different skin manifestations, and for that, a prospective study is in progress. In France, Henry et al. [32] reported a similar case; however, the urticarial rash in this patient was inaugural. The only associated symptoms were odynophagia and arthralgia. This eruption was in the form of disseminated erythematous plaques with facial and acral localization. Estébanez et al. [33] published another type of cutaneous manifestation: lesions in the form of yellowish erythematous papules located in the heels. A very recent publication in Italy [34] suggested that papulovesicular eruption (varicella-like) was rare but specific to COVID-19. Twenty-two patients have been reported with the same clinical presentation; itching was present in $40.9 \%$ of patients. And the eruption was generally localized at the trunk. Another article by the same authors [35] detailed the case of a little girl who has papulovesicular skin eruption on the trunk, face, and genital tract (Figure 2); after 6 days, the patient had a moderate fever and was tested positive for SARS-CoV-2.

Sanchez et al. [37] described a new clinical presentation of skin lesions associated with COVID-19. They reported a skin eruption similar to that of pityriasis rosea: erythematous and squamous plaque, in the trunk, upper arms, and periumbilical.

A Spanish publication has classified the skin lesions observed during COVID-19 into 5 types: maculopapular eruptions in $47 \%$ of cases, urticarial lesions in $19 \%$ of cases, acral areas of erythema with vesicles or pustules in $19 \%$, other vesicular eruptions in $9 \%$, and livedo or necrosis in $6 \%$ [29].
In the pediatric population, the frequency of coronavirus infection is estimated to be less frequent than adults $(<1 \%)$ $[22,44]$. A particular presentation has been reported in children in Europe and North Africa, with a lesion similar to Kawasaki syndrome [38, 44, 45].

Hence, the WHO established a preliminary definition and case for multisystem inflammatory disorder in children and adolescents [44] to help define and recognize these cases for better management and possible surveillance.

Clinical presentation includes fever, rash, mucosal inflammation associated with gastrointestinal problems, myocardial dysfunction, and sometimes even hypotension or shock [44].

According to a French series, concerning 16 children with this syndrome, the skin rash was present in $81 \%$ of patients, edema with plantar and palmar redness was present in $67 \%$ of patients, and $87 \%$ of them had dry lips [38].

As part of this syndrome, the skin eruption can be very varied; for example, an erythema multiforme rash has been described in a 13-year-old patient [39].

Other lesions have also been reported, such as androgenic alopecia (AAG) [40], sebopsoriasis, herpes, and exanthem [41]. Also, nonspecific erythematous lesions in the trunk and face have been described [2].

3.2. Skin Damages among Healthcare Workers. To control this infection, all personnel must wear personal protective equipment (PPE) for an extended period in addition to other safety and health measures. Eczema is the most common problem among healthcare workers [10], often secondary to frequent hand hygiene and long-time gloves wearing [46]. Besides, humidity, prolonged contact with masks, and goggles may cause a variety of cutaneous diseases such as 


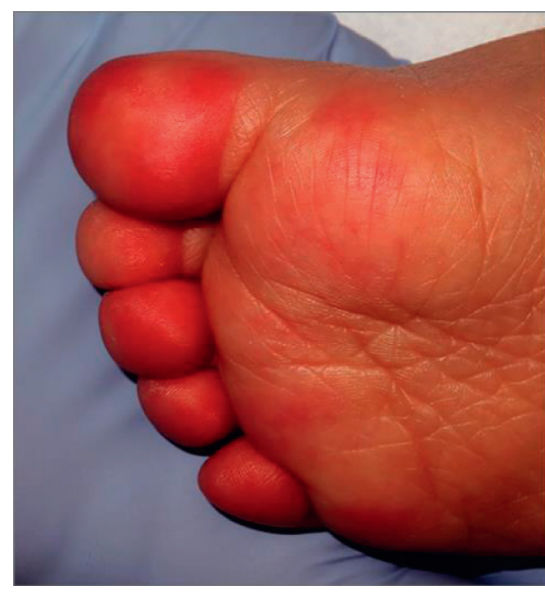

(a)

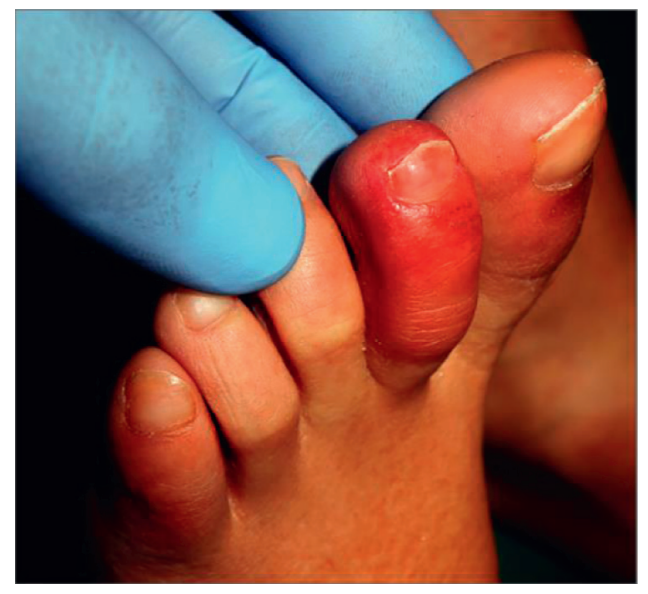

(b)

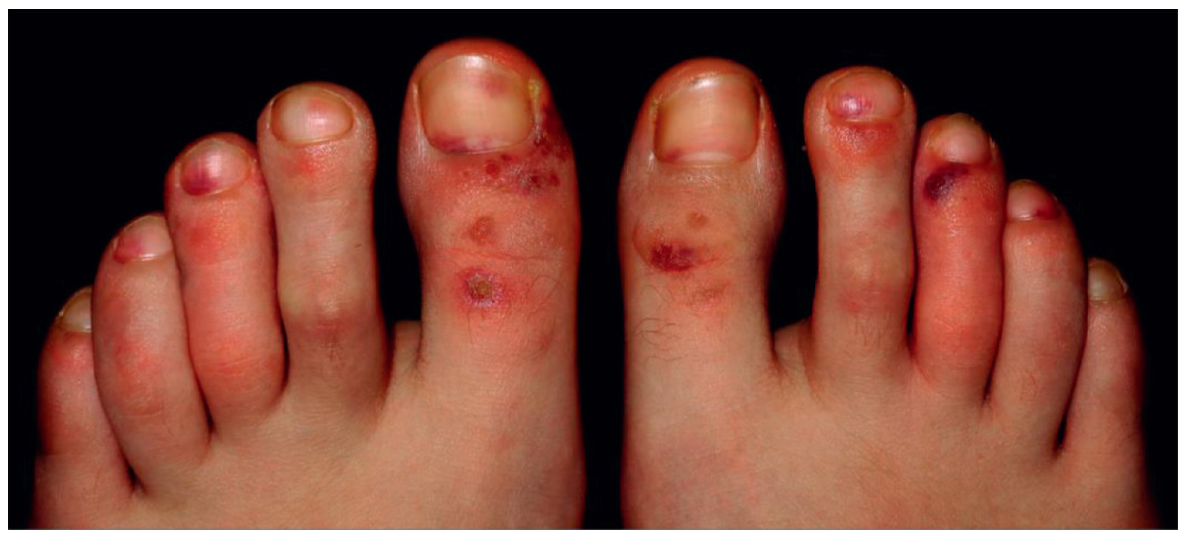

(c)

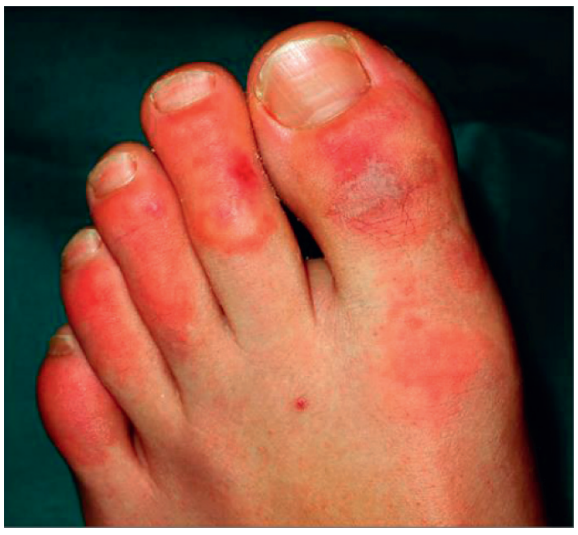

(d)

FIGURE 2: Details of the clinical spectrum (reused from Roca-Ginés et al. JAMA Dermatology 2020 [30]; reference under the terms of the CC-BY license, which permits unrestricted use, distribution, and reproduction in any medium). (a) Acral erythema pattern. (b) Dactylitis pattern. (c) Maculopapular purpuric pattern. (d) Mixed patterns.

contact and pressure urticaria or contact dermatitis and pigmentation of the nasal bridge $[3,11]$. In a survey study [12], Lan et al. found that 526 participants among healthcare professionals mentioned that they had damaged skin. The nasal bridge was the most affected area and then hands, cheek, and forehead. Dryness and desquamation were the most common symptoms, and these damages depended on the hours of work, especially for gloves wearing.
Another questionnaire distributed among 66 patients objected that wearing of masks has caused in $95.1 \%$ of cases side effects including first, nasal bridge scar. Wearing of gloves has caused in $88.5 \%$ of cases skin reactions [47]. We are currently carrying out a study to clarify the consequences of wearing personal protective equipment on the skin. To date, 268 health personnel have completed the questionnaire. Because of frequent handwashing to prevent the disease, dry skin was present in $68.3 \%$, with erythema in $31.3 \%$ of cases (Figure 3 ). 


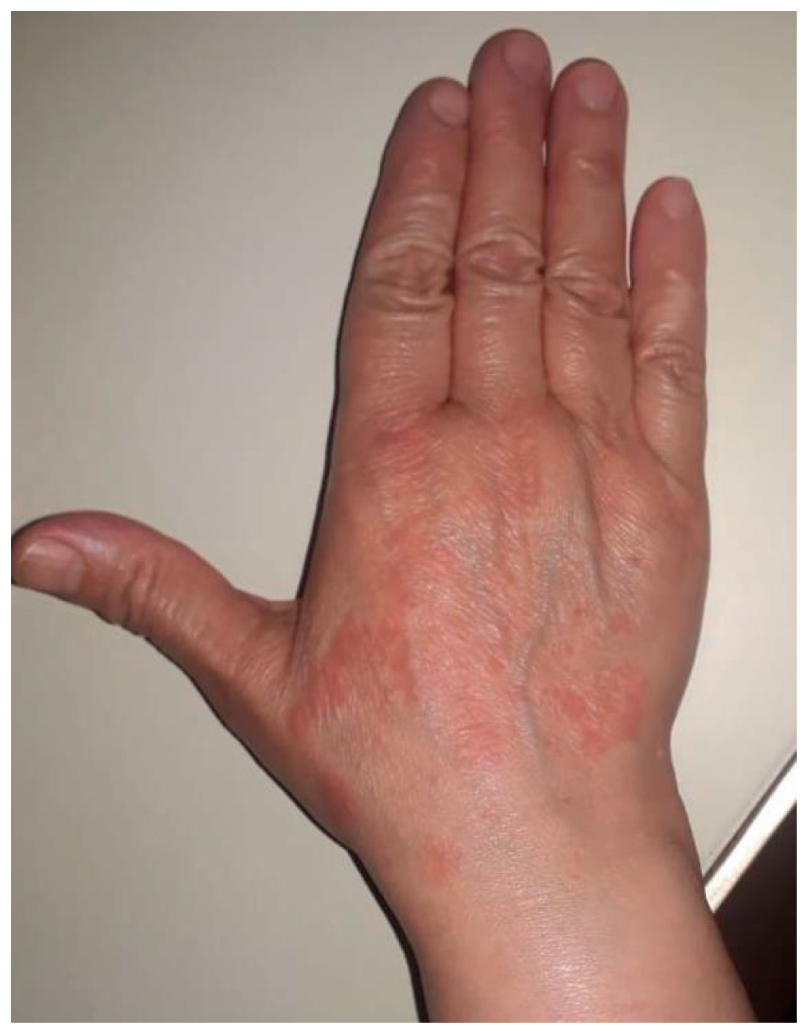

FIGURE 3: Contact dermatitis caused by chemical materials in latex gloves (picture is from our department; written consent was provided by the participant).

\subsection{Aggravation of Previous Skin Diseases during COVID-19.} Exacerbations of preexisting dermatoses such as acne, rosacea, atopic dermatitis, and neurodermatitis have been observed [3,7]. This can be explained by the prolonged wearing of masks during the epidemic. The occlusion generated by protective hats may provoke pruritus and folliculitis or exacerbate seborrheic dermatitis [11], and the frequent use of disinfectant and soap can impair the hydrolipid mantle of the skin and increase the risk of contact dermatitis [7]. The current stress generated by the global situation and confinement can also exacerbate dermatoses [12].

\subsection{Skin Reactions Associated with Different COVID-19} Treatments. Preventive measures are currently the best strategy to fight COVID-19. While vaccines and monoclonal antibodies against SARS-CoV-2 are under development, several other therapies are proposed $[48,49]$, hence the interest to review the skin side effects of these molecules. Chloroquine/hydroxychloroquine (HCQ), a widely used antimalarial and autoimmune disease drug, has been demonstrated to inhibit SARS-CoV-2 and blocks viral activity by increasing endosomal $\mathrm{pH}$ [48-50]. However, the use of this drug remains controversial; some studies have tried to prove the effectiveness of this treatment [48, 50-52]. Nevertheless, each had methodological deficiencies [53]. Other studies are underway with a large sample. Chloroquine is widely used in dermatology disorders and autoimmune disease; its toxicity is infrequent [54], and reactions can be mainly gastrointestinal and cutaneous (pruritus or urticaria), usually mild $[54,55]$. Few cases of HCQ toxidermia have been reported. Acute generalized exanthematous pustulosis (AGEP) was the most common presentation [56, 57]; it appears like a sterile nonfollicular pustule with an erythematous base [58]. Also, drug reactions with eosinophilia and systemic symptoms (DRESS) have been described in four reports [58]. Besides, rare cases of HCQ and Sweet syndrome have also been reported $[6,59]$. The Moroccan Health Ministry and National Technical Committee for Prevention and Control of COVID-19 decided on March 23, 2020, to adopt the therapeutic protocol based on using hydroxychloroquine under medical supervision, and no problem has been noticed yet. Other prescription drugs such as OTC, antibiotics, healthcare products, and a variety of plants can also cause a skin reaction. Zheng and Lai [7] reported cases of urticaria, urticarial vasculitis, and other pruritus lesions in coronavirus pneumonia patients after accepting anti-COVID-19 medicines.

\section{Management of Dermatological Manifestations Associated with COVID-19}

Healthcare institutions and policymakers developed various plans to control the pandemic, including preparing hospitals and clinics, developing a strategy for the identification of suspected COVID-19 cases, and implementing a strategy to reduce the spread [24]. Prevention of nosocomial infection should be another priority; this will require specialized protocols and training of the medical staff. In most countries, several dermatological services have been transformed into a structure for the treatment and isolation of patients with COVID-19 infection, and many private dermatology practices have closed doors [3]. Different solutions have been proposed.

4.1. Patient Management. During the COVID-19 epidemic in China, Wang et al. [60] reported a series of 138 hospitalized patients $(41.3 \%)$ were presumed to have been infected at the hospital, and $29 \%$ of them were healthcare workers. For new patients and outpatients, a preexamination and triage stations at the hospital entrance have been proposed to minimize nosocomial infection and contact [3, 61-63]. Digital technology seemed like a right solution for nonemergency patients $[3,61,62]$. A recently published Swiss study before the COVID-19 outbreak [64] revealed that over $75 \%$ of the patients were interested in using telehealthcare (medical consultations and electronically transmitted prescriptions). During a patient visit, the dermatologist and the patient should both wear a surgical mask with hand hygiene. The dermoscopy should be performed with caution and only if necessary to prevent dermatoscope from becoming a possible source of nosocomial spread [65]. In addition, this exam should be avoided for specific sites such as hands, nails, face, eyes, and mucosa, and for all patients with signs and symptoms suggestive of COVID-19 [65]. 
Several skin diseases, such as psoriasis, as well as depression and anxiety, can increase the risk of $2019-\mathrm{nCoV}$ infection [61, 66]. Phototherapy and the other hospital treatments are needed to be adjusted to avoid displacement [7]. Up until today, there is not enough evidence or guidelines for managing the patients with severe inflammatory skin disorders treated with immunomodulators during this pandemic, and there is no proof that these persons may have a more increased risk of becoming infected with COVID-19 [8, 9, 61]. The first treatment option in this particular period must be the one who has lower effects on personal immune functions such as IL-17 inhibitor [7]. Other treatment options include decreasing the dosage of traditional immunosuppressants (methotrexate and cyclosporine) [8]. On the other hand, there has not been any recommendation or indication justified to stop or reduce the systemic corticosteroid dose [8].

In the case of skin cancer, surgical treatment, if indicated, should not be delayed, especially in critical localization [67].

\subsection{Preventive Measures for Cutaneous Complications Related} to Personal Protective Equipment. The wearing of the PPE for an extended period and the cutaneous complications that generate with stress and anxiety can reduce the efficiency of the health workforce [10]. As such, it has been recommended to use latex-free gloves or use of cotton gloves inside it to avoid cutaneous hand problems. Moreover, the use of cleansing products containing moisturizing ingredients and the application of hand cream frequently are highly recommended $[3,11,68]$. The alcohol hand sanitizers may be used more frequently as they have been shown to be less irritating than washing hands with soap [69]. To avoid friction and pressure from wearing the mask, it has been suggested to wear a properly fitted mask, in different ways, and apply moisturizers or gel just before $[10,11]$, or combine a paper towel with facial mask [67].

4.3. Medical Education and Care in Dermatology. The medical training of future doctors and the scientific communication between dermatologists have also been affected. In Morocco, the Ministry of National Education has deployed an online platform for continued remote instruction for students. The Department of Dermatology and Allergology of the Ludwig Maximilian University Hospital [70] has presented numerous online case studies and offered opportunities for continuous education. Other similar projects with different features and focus already exist on the Internet [71].

\section{Conclusion}

To date, several skin manifestations related to COVID-19 have been reported, but additional efforts are needed to collect further data. It is essential not to forget the patients who suffer from other skin diseases and to insist on preventive measures for healthcare professionals.

\section{Data Availability}

No data were used to support this study.

\section{Conflicts of Interest}

The authors declare no conflicts of interest.

\section{References}

[1] H. A. Rothan and S. N. Byrareddy, "The epidemiology and pathogenesis of coronavirus disease (COVID-19) outbreak," Journal of Autoimmunity, vol. 109, Article ID 102433, 2020.

[2] S. Recalcati, "Cutaneous manifestations in COVID-19: a first perspective," Journal of the European Academy of Dermatology and Venereology, vol. 34, no. 5, 2020.

[3] R. Darlenski and N. Tsankov, "COVID-19 pandemic and the skin: what should dermatologists know?" Clinics in Dermatology, In press.

[4] B. Joob and V. Wiwanitkit, "COVID-19 can present with a rash and be mistaken for dengue," Journal of the American Academy of Dermatology, vol. 82, no. 5, p. e177, 2020.

[5] L. Beylot-Barry, "COVID-19 et lésions cutanées-point d'étape COVIDSKIN de la SFD_15 avril 2020," 2020, https:// evenements-sfd.fr/?mailpoet_router\&endpoint=view_in_ browser\&action $=$ view\&data $=$ WzE5NywiNmZmMmE4ZTA4YzIyliww LDAsMTQzLDFd\&utm_source=mailpoet\&utm_ medium=email\&utm_campaign=actualites-sfd-coronaviruscovid-19-mars-2020_176.

[6] Q. Bodard, D. Carre, P. Chenal et al., "Syndrome de Sweet médicamenteux à l'hydroxychloroquine: à propos de 2 cas," La Revue de Médecine Interne, vol. 39, pp. A171-A172, 2018.

[7] Y. Zheng and W. Lai, "Dermatology staff participate in fight against COVID-19 in China," Journal of the European Academy of Dermatology and Venereology, vol. 34, no. 5, pp. e210-e211, 2020.

[8] M. Rademaker, C. Baker, P. Foley, J. Sullivan, and C. Wang, "Advice regarding COVID-19 and use of immunomodulators, in patients with severe dermatological diseases," Australasian Journal of Dermatology, vol. 61, no. 2, pp. 158-159, 2020.

[9] A. Wollenberg, C. Flohr, D. Simon et al., "European task force on atopic dermatitis statement on severe acute respiratory syndrome coronavirus 2 (SARS-CoV-2) infection and atopic dermatitis," Journal of the European Academy of Dermatology and Venereology, vol. 34, no. 6, pp. e241-e242, 2020.

[10] D. M. Elston, "Occupational skin disease among health care workers during the coronavirus (COVID-19) epidemic," Journal of the American Academy of Dermatology, vol. 82, no. 5, pp. 1085-1086, 2020.

[11] Y. Yan, H. Chen, L. Chen et al., "Consensus of Chinese experts on protection of skin and mucous membrane barrier for healthcare workers fighting against coronavirus disease 2019," Dermatologic Therapy, In press.

[12] J. Lan, Z. Song, X. Miao et al., "Skin damage among health care workers managing coronavirus disease-2019," Journal of the American Academy of Dermatology, vol. 82, no. 5, pp. 1215-1216, 2020.

[13] WHO, "Coronavirus disease (COVID-19) situation report167,” 2020, https://www.who.int/docs/default-source/ coronaviruse/situation-reports/20200705-covid-19-sitrep167.pdf?sfvrsn=17e7e3df_4. 
[14] Y. Fu, Y. Cheng, and Y. Wu, "Understanding SARS-CoV-2mediated inflammatory responses: from mechanisms to potential therapeutic tools," Virologica Sinica, vol. 35, no. 3, pp. 266-271, 2020.

[15] A. Vabret, J. Dina, E. Brison, J. Brouard, and F. Freymuth, "Coronavirus humains (HCoV)," Pathologie Biologie, vol. 57, no. 2, pp. 149-160, 2009.

[16] R. J. G. Hulswit, C. A. M. de Haan, and B.-J. Bosch, "Coronavirus spike protein and tropism changes," Coronaviruses, Elsevier, Amsterdam, Netherlands, 2016.

[17] M. Zhou, X. Zhang, and J. Qu, "Coronavirus disease 2019 (COVID-19): a clinical update," Frontiers of Medicine, vol. 14, no. 2, pp. 126-135, 2020.

[18] G. Li, Y. Fan, Y. Lai et al., "Coronavirus infections and immune responses," Journal of Medical Virology, vol. 92, no. 4, pp. 424-432, 2020.

[19] K. Wang, W. Chen, Y.-S. Zhou et al., "SARS-CoV-2 invades host cells via a novel route: CD147-spike protein," Microbiology, In press.

[20] I. Hamming, W. Timens, M. Bulthuis, A. Lely, G. Navis, and H. van Goor, "Tissue distribution of ACE2 protein, the functional receptor for SARS coronavirus. A first step in understanding SARS pathogenesis," The Journal of Pathology, vol. 203, no. 2, pp. 631-637, 2004.

[21] C. Huang, Y. Wang, X. Li et al., "Clinical features of patients infected with 2019 novel coronavirus in Wuhan, China," The Lancet, vol. 395, no. 10223, pp. 497-506, 2020.

[22] G. Kaya, A. Kaya, and J.-H. Saurat, "Clinical and histopathological features and potential pathological mechanisms of skin lesions in COVID-19: review of the literature," Dermatopathology, vol. 7, no. 1, pp. 3-16, 2020.

[23] L. Wenzhong and L. Hualan, "COVID-19: attacks the 1-beta chain of hemoglobin and captures the porphyrin to inhibit human heme metabolism," In press.

[24] L. Rudnicka, M. Gupta, M. Kassir et al., "Priorities for global health community in COVID-19 pandemic," Dermatologic Therapy, Article ID e13361, In press.

[25] Y.-R. Guo, Q.-D. Cao, Z.-S. Hong et al., "The origin, transmission and clinical therapies on coronavirus disease 2019 (COVID-19) outbreak-an update on the status," Military Medical Research, vol. 7, no. 1, pp. 11-13, 2020.

[26] Y. Zhang, W. Cao, M. Xiao et al., "Clinical and coagulation characteristics in 7 patients with critical COVID-2019 pneumonia and acro-ischemia," Chinese Journal of Hematology, vol. 41, no. 4, pp. 302-307, 2020.

[27] E. E. Freeman, D. E. McMahon, J. B. Lipoff et al., "Pernio-like skin lesions associated with COVID-19: a case series of 318 patients from 8 countries," Journal of the American Academy of Dermatology, vol. 83, no. 2, pp. 486-492, 2020.

[28] V. Piccolo, I. Neri, C. Filippeschi et al., "Chilblain-like lesions during COVID-19 epidemic: a preliminary study on 63 patients," Journal of the European Academy of Dermatology and Venereology, vol. 34, no. 7, 2020.

[29] C. Galván Casas, A. Català, G. Carretero Hernández et al., "Classification of the cutaneous manifestations of COVID-19: a rapid prospective nationwide consensus study in Spain with 375 cases," British Journal of Dermatology, vol. 183, no. 1, pp. 71-77, 2020.

[30] J. Roca-Ginés, I. Torres-Navarro, J. Sánchez-Arráez et al., "Assessment of acute acral lesions in a case series of children and adolescents during the COVID-19 pandemic," JAMA Dermatology, In press.

[31] D. Fernandez-Nieto, D. Ortega-Quijano, G. Segurado-Miravalles, C. Pindado-Ortega, M. Prieto-Barrios, and J. Jimenez-
Cauhe, "Comment on: cutaneous manifestations in COVID19: a first perspective. Safety concerns of clinical images and skin biopsies," Journal of the European Academy of Dermatology and Venereology, vol. 34, no. 6, pp. e252-e254, 2020.

[32] D. Henry, M. Ackerman, E. Sancelme, A. Finon, and E. Esteve, "Urticarial eruption in COVID-19 infection," Journal of the European Academy of Dermatology and Venereology, vol. 34, no. 6, pp. e244-e245, 2020.

[33] A. Estébanez, L. Pérez-Santiago, E. Silva, S. Guillen-Climent, A. García-Vázquez, and M. D. Ramón, "Cutaneous manifestations in COVID-19: a new contribution," Journal of the European Academy of Dermatology and Venereology, vol. 34, no. 6, pp. e250-e251, 2020.

[34] A. V. Marzano, G. Genovese, G. Fabbrocini et al., "Varicellalike exanthem as a specific COVID-19-associated skin manifestation: multicenter case series of 22 patients," Journal of the American Academy of Dermatology, vol. 83, no. 1, pp. 280-285, 2020.

[35] G. Genovese, C. Colonna, and A. V. Marzano, "Varicella-like exanthem associated with COVID-19 in an 8-year-old girl: a diagnostic clue?" Pediatric Dermatology, vol. 37, no. 3, pp. 435-436, 2020

[36] D. Fernandez-Nieto, J. Jimenez-Cauhe, A. Suarez-Valle et al., "Comment on "Characterization of acute acro-ischemic lesions in non-hospitalized patients: a case series of 132 patients during the COVID-19 outbreak"' Journal of the American Academy of Dermatology, In press.

[37] A. Sanchez, P. Sohier, S. Benghanem et al., "Digitate papulosquamous eruption associated with severe acute respiratory syndrome coronavirus 2 infection," JAMA Dermatology, vol. 156, no. 7, p. 819, 2020.

[38] M. Pouletty, C. Borocco, N. Ouldali et al., "Paediatric multisystem inflammatory syndrome temporally associated with SARS-CoV-2 mimicking Kawasaki disease (Kawa-COVID19): a multicentre cohort," Annals of the Rheumatic Diseases, vol. 79, no. 8, pp. 999-1006, 2020.

[39] T. Bapst, F. Romano, M. Müller, and M. Rohr, "Special dermatological presentation of paediatric multisystem inflammatory syndrome related to COVID-19: erythema multiforme," BMJ Case Reports, vol. 13, no. 6, Article ID e236986, 2020.

[40] A. Goren, S. Vaño-Galván, C. G. Wambier et al., "A preliminary observation: male pattern hair loss among hospitalized COVID-19 patients in Spain-a potential clue to the role of androgens in COVID-19 severity," Journal of Cosmetic Dermatology, vol. 19, no. 7, pp. 1545-1547, 2020.

[41] V. Gaspari, I. Neri, C. Misciali, and A. Patrizi, "COVID-19: how it can look on the skin. Clinical and pathological features in 20 COVID-19 patients observed in Bologna, north-eastern Italy," Journal of the European Academy of Dermatology and Venereology, In press.

[42] U. Wollina, A. S. Karadağ, C. Rowland-Payne, A. Chiriac, and T. Lotti, "Cutaneous signs in COVID-19 patients: a review," Dermatologic Therapy, Article ID e13549, In press.

[43] N. Tang, H. Bai, X. Chen, J. Gong, D. Li, and Z. Sun, "Anticoagulant treatment is associated with decreased mortality in severe coronavirus disease 2019 patients with coagulopathy," Journal of Thrombosis and Haemostasis, vol. 18, no. 5, pp. 1094-1099, 2020.

[44] WHO, "Multisystem inflammatory syndrome in children and adolescents temporally related to COVID-19," 2020, https:// www.who.int/news-room/commentaries/detail/multisysteminflammatory-syndrome-in-children-and-adolescents-withcovid-19. 
[45] S. Riphagen, X. Gomez, C. Gonzalez-Martinez, N. Wilkinson, and P. Theocharis, "Hyperinflammatory shock in children during COVID-19 pandemic," The Lancet, vol. 395, no. 10237, pp. 1607-1608, 2020.

[46] M.-A. Flyvholm, B. Bach, M. Rose, and K. F. Jepsen, "Selfreported hand eczema in a hospital population," Contact Dermatitis, vol. 57, no. 2, pp. 110-115, 2007.

[47] K. Hu, J. Fan, X. Li, X. Gou, X. Li, and X. Zhou, "The adverse skin reactions of health care workers using personal protective equipment for COVID-19," Medicine (Baltimore), vol. 99, no. 24, Article ID e20603, 2020.

[48] J. Gao, Z. Tian, and X. Yang, "Breakthrough: chloroquine phosphate has shown apparent efficacy in treatment of COVID-19 associated pneumonia in clinical studies," BioScience Trends, vol. 14, no. 1, pp. 72-73, 2020.

[49] M. Wang, R. Cao, L. Zhang et al., "Remdesivir and chloroquine effectively inhibit the recently emerged novel coronavirus (2019-nCoV) in vitro," Cell Research, vol. 30, no. 3, pp. 269-271, 2020.

[50] P. Gautret, J.-C. Lagier, P. Parola et al., "Hydroxychloroquine and azithromycin as a treatment of COVID-19: results of an open-label non-randomized clinical trial," International Journal of Antimicrobial Agents, Article ID 105949, In press.

[51] J. Chen, L. Danping, L. Liu et al., "A pilot study of hydroxychloroquine in treatment of patients with moderate COVID19," Journal of ZheJiang Univercity (Medical Sciences), vol. 49, no. 2, pp. 215-219, 2020.

[52] Z. Chen, J. Hu, Z. Zhang et al., "Efficacy of hydroxychloroquine in patients with COVID-19: results of a randomized clinical trial," medRxiv, In press.

[53] K. Gbinigie and K. Frie, "Should chloroquine and hydroxychloroquine be used to treat COVID-19? A rapid review," BJGP Open, vol. 4, no. 2, 2020.

[54] G. Ruiz-Irastorza, M. Ramos-Casals, P. Brito-Zeron, and M. A. Khamashta, "Clinical efficacy and side effects of antimalarials in systemic lupus erythematosus: a systematic review," Annals of the Rheumatic Diseases, vol. 69, no. 1, pp. 20-28, 2010.

[55] N. Costedoat-Chalumeau, L. Galicier, O. Aumaître et al., "Hydroxychloroquine in systemic lupus erythematosus: results of a French multicentre controlled trial (PLUS study)," Annals of the Rheumatic Diseases, vol. 72, no. 11, pp. 17861792, 2013.

[56] A. Paradisi, L. Bugatti, T. Sisto, G. Filosa, P. L. Amerio, and R. Capizzi, "Acute generalized exanthematous pustulosis induced by hydroxychloroquine: three cases and a review of the literature," Clinical Therapeutics, vol. 30, no. 5, pp. 930-940, 2008.

[57] R. A. Schwartz and C. K. Janniger, "Generalized pustular figurate erythema: a newly delineated severe cutaneous drug reaction linked with hydroxychloroquine," Dermatologic Therapy, vol. 33, no. 3, Article ID e13380, 2020.

[58] R. L. Girijala, I. Siddiqi, Y. Kwak, D. Wright, D. B. Patel, and L. H. Goldberg, "Pustular DRESS syndrome secondary to hydroxychloroquine with EBV reactivation," Journal of Drugs in Dermatology, vol. 18, no. 2, pp. 207-209, 2019.

[59] C. Manzo, N. Pollio, and M. Natale, "Sweet's syndrome following therapy with hydroxychloroquine in a patient affected with elderly-onset primary sjogren's syndrome," Medicines, vol. 6, no. 4, p. 111, 2019.

[60] D. Wang, B. Hu, C. Hu et al., "Clinical characteristics of 138 hospitalized patients with 2019 novel coronavirus-infected pneumonia in Wuhan, China," Jama, vol. 323, no. 11, p. 1061, 2020.
[61] J. Tao, Z. Song, L. Yang, C. Huang, A. Feng, and X. Man, "Emergency management for preventing and controlling nosocomial infection of the 2019 novel coronavirus: implications for the dermatology department," British Journal of Dermatology, vol. 182, no. 6, pp. 1477-1478, 2020.

[62] J. T. Pathoulas, B. K. Stoff, K. C. Lee, and R. S. Farah, "Ethical outpatient dermatology care during the coronavirus (COVID-19) pandemic," Journal of the American Academy of Dermatology, vol. 82, no. 5, pp. 1272-1273, 2020.

[63] D. M. Elston, "The coronavirus (COVID-19) epidemic and patient safety," Journal of the American Academy of Dermatology, vol. 82, no. 4, pp. 819-820, 2020.

[64] C. Greis, C. Meier Zürcher, V. Djamei, A. Moser, S. Lautenschlager, and A. A. Navarini, "Unmet digital health service needs in dermatology patients," Journal of Dermatological Treatment, vol. 29, no. 7, pp. 643-647, 2018.

[65] D. Jakhar, I. Kaur, and S. Kaul, "Art of performing dermoscopy during the times of coronavirus disease (COVID-19): simple change in approach can save the day!" Journal of the European Academy of Dermatology and Venereology, vol. 34, no. 6, pp. e242-e244, 2020.

[66] G. Kampf and H. Löffler, "Dermatological aspects of a successful introduction and continuation of alcohol-based hand rubs for hygienic hand disinfection," Journal of Hospital Infection, vol. 55, no. 1, pp. 1-7, 2003.

[67] U. Wollina, "Challenges of COVID-19 pandemic for dermatology," Dermatologic Therapy, Article ID e13430, In press.

[68] G. Cavanagh and C. G. Wambier, "Rational hand hygiene during the coronavirus 2019 (COVID-19) pandemic," Journal of the American Academy of Dermatology, vol. 82, no. 6, p. e211, 2020.

[69] M. K. Gupta and S. R. Lipner, "Personal protective equipment recommendations based on COVID-19 route of transmission," Journal of the American Academy of Dermatology, vol. 83, no. 1, pp. e45-e46, 2020.

[70] M. Reinholz and L. E. French, "Medical education and care in dermatology during the SARS-CoV2 pandemia: challenges and chances," Journal of the European Academy of Dermatology and Venereology, vol. 34, no. 5, pp. e214-e216, 2020.

[71] U. Bader, C. Cipolat, and G. Burg, "5.2.1. Dermatology Online with Interactive Technology (DOIT)," Telemedicine and Teledermatology, Kargar International, Basel, Switzerland, 2002. 